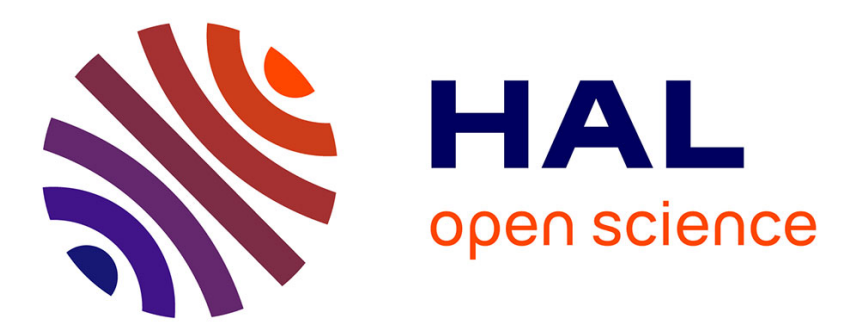

\title{
Stereotype Threat Alters the Subjective Experience of Memory
}

Marie Mazerolle, Isabelle Régner, François Rigalleau, Pascal Huguet

\section{To cite this version:}

Marie Mazerolle, Isabelle Régner, François Rigalleau, Pascal Huguet. Stereotype Threat Alters the Subjective Experience of Memory. Experimental Psychology, 2015, 62 (6), pp.395-402. 10.1027/16183169/a000303 . hal-01341814

\section{HAL Id: hal-01341814 https://hal.science/hal-01341814}

Submitted on 4 Jul 2016

HAL is a multi-disciplinary open access archive for the deposit and dissemination of scientific research documents, whether they are published or not. The documents may come from teaching and research institutions in France or abroad, or from public or private research centers.
L'archive ouverte pluridisciplinaire HAL, est destinée au dépôt et à la diffusion de documents scientifiques de niveau recherche, publiés ou non, émanant des établissements d'enseignement et de recherche français ou étrangers, des laboratoires publics ou privés. 
Running head: STEREOTYPE THREAT AND MEMORY

Stereotype Threat Alters the Subjective Experience of Memory

Marie Mazerolle $^{1}$, Isabelle Régner ${ }^{2}$, François Rigalleau ${ }^{1}$, and Pascal Huguet ${ }^{2}$

${ }^{1}$ University of Poitiers and National Center for Scientific Research (CNRS)

${ }^{2}$ Aix-Marseille University and National Center for Scientific Research (CNRS)

\begin{abstract}
Author Note
This work was supported by the Fondation "Plan Alzheimer" (AAP-SHS 2013).

We thank Sarah J. Barber as well as an anonymous reviewer for their constructive comments.

Correspondence concerning this article should be addressed to Marie Mazerolle, University of Poitiers-Psychology, Centre de Recherches sur la Cognition et l'Apprentissage, 5 Rue Lefebvre, Poitiers 86000, France. Phone:+33549454635. E-mail: marie.mazerolle@univpoitiers.fr
\end{abstract}


Stereotype Threat Alters the Subjective Experience of Memory

The threat to confirm negative stereotypes about one's group may interfere with intellectual functioning and lead to underperformance and stereotype confirmation, an effect called "stereotype threat" (C. M. Steele \& Aronson, 1995; for a review, see Schmader, Johns, $\&$ Forbes, 2008). This effect has been shown with numerous groups and stereotypes, such as women and girls in math (e.g., Ambady, Shih, Kim, \& Pittinsky, 2001; Huguet \& Régner, 2007, 2009; Régner, J. R. Steele, Ambady, Thinus-Blanc, \& Huguet, 2014; Spencer, C. M. Steele, \& Quinn, 1999), students from low socioeconomic backgrounds and ethnic minorities on intellectual tasks (e.g., Croizet \& Claire, 1998; C. M. Steele \& Aronson, 1995), and older adults on memory tests (e.g., Hess, Auman, Colcombe, \& Rahhal, 2003; Mazerolle, Régner, Morisset, Rigalleau, \& Huguet, 2012; Rahhal, Hasher, \& Colcombe, 2001).

There is now growing evidence that negative aging stereotypes contribute to lower older adults' memory performance (Chasteen, Kang, \& Remedios, 2012). These performance deficits occurred when the memory component of the test was emphasized (Desrichard \& Köpetz, 2005; Kang \& Chasteen, 2009; Rahhal et al., 2001), when performance differences between younger and older adults were highlighted (Hess et al., 2003), and when age-related stereotypes about memory were implicitly activated using priming techniques (Levy, 1996; Stein, Blanchard-Fields, \& Hertzog, 2002). Recently, Mazerolle et al. (2012) showed that simply informing older adults about the presence of younger participants (threat condition) decreased older adults' controlled access to memory and simultaneously intensified their use of familiarity processes. Consistent with this, Thomas and Dubois (2012) found that older adults under stereotype threat are indeed more likely than younger adults to falsely remember lures related to studied words, suggesting an increased reliance on Familiarity under threat. 
There is also evidence that stereotype threat facilitates the use of dominant or well-learned (familiar) responses which may improve or deteriorate performance depending on their contextual relevance (Jamieson \& Harkins, 2007; Zajonc, 1965). Likewise, reduced control under threat is consistent with numerous studies indicating that stereotype threat taxes executive resources required for successful performance on difficult tasks (Beilock \& Carr, 2005, Beilock \& DeCaro, 2007; Beilock, Rydell, \& McConnell, 2007; Régner et al., 2010; Schmader \& Johns, 2003; Schmader et al., 2008). Without denying that normal aging can be associated with cognitive decline, all these studies indicate that negative aging stereotypes may produce inflated age differences in memory tasks through relatively distinct yet not necessarily antagonistic mechanisms (since impaired controlled processes may coexist with increased Familiarity).

\section{The Present Research}

Stereotype threat may not just influence memory performance per se, but also the subjective experience of memory (i.e., the basic feeling that one is more or less able to remember). This is a critical issue since doubts about one's memory ability in daily life probably start with the impression of being unable to remember contextual details or episodic events (e.g., where did I leave my keys? What did he/she ask me to buy at the supermarket? Who is the man on the bus whose face is so familiar to me?). Subjective feelings of memory may be exacerbated by age-related stereotypes predicting that all people experience severe cognitive decline as they age. Hess, Emery and Queen (2009) already examined this possibility using a Remember/Know $(\mathrm{R} / \mathrm{K})$ paradigm, which reflects the subjective state of awareness that accompanies episodic memory retrievals (Gardiner \& Richardson-Klavehn, 2000; Tulving, 1985).

A fundamental distinction in research on episodic memory is between Recollection and Familiarity (Tulving, 1985). Recollection refers to remembering some information plus 
the spatiotemporal context of the episode in which it was acquired. Familiarity refers more to the impression that an event was previously experienced (Wixted \& Mickes, 2010; Yonelinas, 2002) while failing to recall any detail about the context of this event. The best example of Familiarity — the butcher-on-the-bus phenomenon — occurs when one believes that a person is so familiar that it compels a memory search while failing to recall any information about that person whatsoever (often upon seeing their face in an atypical context). In the R/K paradigm, previously learned items are to be classified as remember if the item is recollected with a detail of its presentation context (e.g., the position of the item in the list, or something that the item reminds when it is presented). A know response is to be given to items that seem familiar, but for which no contextual details are recollected.

According to the literature on aging using $\mathrm{R} / \mathrm{K}$ paradigm, remember responses decrease with aging, whereas know responses remain stable otherwise slightly increase (for a review, see Yonelinas, 2002). This well-known pattern has been thought to reflect either frontal lobe dysfunction or deficits at the encoding/retrieval stage of Recollection in older adults (Parkin \& Walter, 1992; Perfect \& Dasgupta, 1997). However, as demonstrated by Hess et al. (2009), this pattern may also reflect the intervention of negative stereotypes about aging. In their research, Hess et al. (2009) found that older adults under stereotype threat produced lower rates of remember responses as compared to a reduced threat condition, at least under time constraints. This strengthens the view that caution is required when interpreting older adults' memory performance.

Here we relied on Hess et al.'s (2009) study with the aim of clarifying the exact influence of stereotype threat in the R/K paradigm. In Hess et al.'s (2009) study, stereotype threat caused lower rates of remember responses but left know responses unchanged. This may seem surprising as many studies in social psychology demonstrated an increase of familiarity and automatic processes under different threat contexts (Belletier et al., 2015; 
Ben-Zeev, Fein, \& Inzlicht, 2005; Conty, Gimmig, Belletier, George, \& Huguet, 2010; Huguet, Barbet, Belletier, Monteil, \& Fagot, 2014; Zajonc, 1965), including stereotype threat (Jamieson \& Harkins, 2007, 2009; Mazerolle et al., 2012). We suspect that Hess et al.’s (2009) method actually underestimated Familiarity, which would explain the lack of stereotype threat effects on the know responses in their research.

First, Hess et al. restricted Familiarity to know responses. As noted by Yonelinas and Jacoby (1995), know responses do not provide a pure measure of Familiarity because they only reflect Familiarity in the absence of Recollection. This excludes the possibility that some remember responses were also familiar, know responses therefore typically underestimate Familiarity. To correct this underestimation, Yonelinas and Jacoby (1995) proposed to divide the proportion of know responses by the opportunity the subject has to make a know response $(1-R)$ : $F=$ know/(1 - remember $)$. It is noteworthy that Hess et al. (2009) used another formula to compute Familiarity ( $k$ now old $\left.-k n o W_{\text {new }}\right)$, and failed to find a significant stereotype threat effect. We do not argue that Hess et al.'s (2009) Familiarity estimate is irrelevant. Instead, based on Yonelinas and Jacoby (1995), we argue that this estimate neglects the possibility that some remember responses were also familiar. It cannot be ruled out that this underestimation of Familiarity made the detection of stereotype threat effects unlikely.

Second, Hess et al.'s (2009) study included a 10 minutes retention interval between the learning and recognition phases, which is thought to deteriorate Familiarity. In Yonelinas and Levy's (2002) study, Familiarity, but not Recollection, indeed decreased as study-test lag increased. Furthermore, Eichenbaum, Yonelinas and Ranganath (2007) reported that, for monkeys, after a 5 minutes delay, the perirhinal cortex (supporting familiarity) decreased more than the parahippocampal cortex (supporting Recollection), strengthening the idea that familiarity decreases more rapidly over time, at least for delays inferior to 10 minutes. 
Third, Hess et al. (2009) also added a guess response modality to avoid participants to respond know when they were uncertain of their response. If some papers recommend using a guess response modality, others suggest that guess responses are not fundamentally different from know responses (Hirshman, 1998), as they are often justified as familiarity-based.

All these methodological details may have limited Hess et al.'s (2009) possibility to observe stereotype threat effects on Familiarity, as also suggested by their relatively low Familiarity estimates (below .10 in all conditions), which is unusual (Yonelinas, 2002). This is why we decided not to include any retention interval between the learning and recognition phases and any guess response modality. In short, Hess et al.'s (2009) study offers the first evidence that stereotype threat matters in the $\mathrm{R} / \mathrm{K}$ paradigm, but does not necessarily speak to the ultimate fate of Familiarity under threat in this paradigm.

Finally, to assess the magnitude of the age-related difference in the threat and reduced threat conditions, younger participants were also included in the present research (only older adults participated in Hess et al.'s study). After all, if stereotype threat contributes to the agerelated differences in the $\mathrm{R} / \mathrm{K}$ paradigm (at least on the $\mathrm{R}$ responses), these differences should be reduced in a reduced threat condition.

\section{Method}

\section{Participants}

Forty younger adults (19 to 28 years, mean age $=21$ years, $S D=2.09$ ) and thirty-eight older adults ( 60 to 83 years, mean $_{\text {age }}=69.33$ years, $\left.S D=5.71\right)$ were included in the study. Younger participants were recruited from the student population and older adults were recruited from the community via direct phone call. Younger and older adults did not differ in years of education ( $M=14$ vs. 13.43 years respectively, $F<1$ ). All the older participants lived at home, were french native speakers, and obtained a score greater than 27 at the MiniMental State Examination (MMSE) in the 6 previous months (while they were involved in a 
study about the impact of physical activity on cognitive functioning). We used this previous MMSE score because it is recommended to observe a period of one full year before retesting participants on the MMSE (Tombaugh \& McIntyre, 1992). It is noteworthy that using this previous score also prevented any interference between the way participants evaluated themselves on the MMSE and the R/K task. Importantly, none of the participants were previously exposed to a stereotype threat manipulation or informed about the impact of stereotypes on memory/cognitive performance. No participant was taking medications for mental or emotional problems at the time of testing.

\section{Material and procedure}

To ensure that participants randomly assigned to the threat versus reduced threat condition would not differ regarding their working memory capacity, they first completed a french version of the Reading Span test prior to taking part in the study (Delaloye, Ludwig, Borella, Chicherio, \& de Ribaupierre, 2008; for the details, see Mazerolle et al., 2012). Participants were told that this task was "under construction", thereby suggesting that the purpose of the evaluation was the task rather than participants themselves (a procedure that proved successful for reducing socio-evaluative threat in other paradigms, see Gimmig, Huguet, Caverni, \& Cury, 2006; Huguet, Galvaing, Monteil, \& Dumas, 1999). Participants assigned to the threat versus reduced threat condition did not differ regarding their working memory capacity.

Then, participants assigned to the threat condition (20 younger and 19 older participants) were told that they were about to perform a memory task and that both younger and older adults would also take part in the study. In the reduced threat condition (20 younger and 19 older participants), the same information was given but participants were also told that performance on this task usually does not differ between younger and older adults (as also did Mazerolle et al., 2012). Reframing the task as age-fair was used to reduce stereotype 
threat in older adults the same way Quinn and Spencer (2001) minimized threat by ensuring women participants that a math test was gender fair. Then participants performed the $\mathrm{R} / \mathrm{K}$ paradigm based on Vann et al. (2009). Participants first heard a list of 50 words, presented one by one by a computer (words were previously recorded by the experimenter). They were asked to indicate on a keyboard the number of letters of each word immediately after its presentation (word count accuracy exceeded $95 \%$ in both younger and older participants) and to remember the words for a later recognition phase. Half a second after, participants decided how many letters composed the word a new word was presented, thereby imposing a rapid pace. Straight after the encoding phase, a recognition test was given in which participants heard 75 words (the 50 words pertaining to the learning list and 25 fillers). First, participants had to decide if the word was pertaining to the learning list (old word) or if it was a new word. Immediately after this first decision, and only when a word was recognized as an old one, participants had to decide if the word was explicitly remembered (i.e., if they were able to remember a detail associated with the prior presentation of the word in the list, remember response), or if the word simply looked familiar (if they thought they had heard the word earlier but could not remember experiencing it, know response). We assumed that remember and know responses reflect two distinct memory processes (dual-process accounts are corroborated by numerous studies, see Yonelinas, 2002) rather than single-process accounts (where remember and know responses are thought to reflect varying levels of confidence). We therefore explicitly mentioned to participants that the difference between remember and know responses was not about their confidence degree, but more about the possibility of remembering details associated with the item (remember) versus only feelings of familiarity (know). Participants noted their answers on a paper sheet. We used 33\% of distracters because we focused on $\mathrm{R} / \mathrm{K}$ judgments and not on false alarms per se. A relatively low 
number of distracters had the advantage of maximizing the number of yes responses and so the number of $\mathrm{R} / \mathrm{K}$ judgments (since there is no $\mathrm{R} / \mathrm{K}$ judgment on the no responses).

To ensure participants understood the instructions, they were required to explain their responses during a training phase. Any confusion between the two judgments ( remember or know) was clarified by additional instructions and examples. Words used at encoding and as distracters were common concrete nouns, unrelated, one third of high frequency, one third of medium frequency, and one third of low frequency (based on Vann et al., 2009; Yonelinas et al., 2002). Therefore, we used a very “classic” RK paradigm. Likewise, because we assumed that guess responses are not fundamentally distinct from know responses (Yonelinas, 2002), we did not provide the guess response option to participants. Finally, participants were debriefed and thanked.

\section{Results}

\section{Estimates of Recollection (R) and Familiarity (F)}

Recollection and Familiarity were estimated following Yonelinas and Jacoby (1995) while controlling for potential differences in false-alarm rates (typically higher in older participants than in their younger counterparts; McCabe, Roediger III, McDaniel, \& Balota, 2009). $R$ was thus estimated as the probability of responding remember to an old word minus the probability of responding remember to a filler (i.e., $R=$ remember $_{\text {old }}-$ remember $_{\text {new }}$ ). $F$ was estimated as the probability of a familiar response given to an old word considering that the item was not recollected (i.e. $F=k$ nowold $/\left(1-\right.$ remember $\left._{o l d}\right)$, minus the same estimate for new items (see Table 1 in Electronic Supplementary Material for the raw data on remember and know responses).

$R$ and $F$ estimates were then analyzed using 2 (Threat condition: threat vs. reduced threat) x 2 (Age group: older vs. younger adults) Analyses of Variance. The ANOVA on $R$ showed a main effect of Age group, $F(1,74)=8.50, p=.005, \eta^{2}=.10: R$ was lower for the 
older participants $(M=.34, S E=.03)$ than for the younger participants $(M=.47, S E=.03)$. The main effect of Threat was not significant. As expected, the Threat by Age group interaction was significant, $F(1,74)=4.87, p=.030, \eta^{2}=.06$ (Fig.1a). $R$ for the older participants was lower in the threat condition than in the reduced threat condition, $F(1,74)=$ $8.42, p=.005, \eta^{2}=.10$, whereas this Recollection estimate did not differ between the two conditions in the younger participants $(F<1)$. In addition, in the threat condition, $R$ was lower for the older participants than for their younger counterparts, $F(1,74)=13.12, p=$ $.001, \eta^{2}=.15$, whereas there was no age difference in the reduced threat condition $(F<1)$.

The same $2 \times 2$ ANOVA on $F$ showed the expected Threat by Age interaction effect,

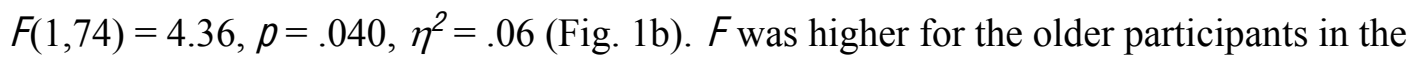
threat condition than in the reduced threat condition, $F(1,74)=5.68, p=.020, \eta^{2}=.07$, whereas the younger participants did not differ across threat conditions $(F<1)$. No other effects reached significance. ${ }^{1}$

\section{Underestimated Familiarity (Knowold-Knownew)}

For comparison purposes, we also analyzed corrected response rates for know responses by subtracting the proportions of know responses to distracters from the same proportions to targets, the indicator of Familiarity retained by Hess et al. (2009). This estimate was analyzed using the same 2 X 2 ANOVA as previously. The main effect of Threat was significant, $F(1,74)=5.33, p=.024, \eta^{2}=.07$, qualified by a Threat $\mathrm{x}$ Age group interaction, $F(1,74)=7.16, p=.009, \eta^{2}=.09$. Corrected response rate for know responses was higher for the older participants in the threat condition $(M=.37, S E=.04)$ than in the reduced threat condition $(M=.18, S E=.04), F(1,74)=12.11, p=.001, \eta^{2}=.14$, whereas the younger participants did not differ across threat conditions $(F<1)$. In addition, in the threat condition, corrected response rate for know responses was higher for the older participants ( $M$ $=.37, S E=.04)$ than for their younger counterparts $(M=.21, S E=.04), F(1,74)=8.82, p=$ 
$.004, \eta^{2}=.11$, whereas there was no age difference in the reduced threat condition (Myoung $=.23, S E=.04 ; F<1)$. It is noteworthy that working memory scores did not moderate any of the above findings whatever the estimates used (Yonelinas \& Jacoby, 1995 or Hess et al., 2009).

\section{Discussion}

As expected, in the Remember/Know $(\mathrm{R} / \mathrm{K})$ paradigm not only did stereotype threat decrease older adults' Recollection $(R)$ but also increased Familiarity $(F)$. This is consistent with Mazerolle et al.'s (2012) results on the process dissociation procedure (Jacoby, 1991), in which stereotype threat undermined older adults' controlled access to memory and simultaneously intensified the use of familiarity processes. In Hess et al.'s (2009) study, stereotype threat also caused lower rates of remember responses but left know responses (taken as estimates of Familiarity) unchanged. We assumed that this discrepancy could result from the fact that Hess et al. (2009) restricted Familiarity to know responses. However, the present findings hold even when using Hess et al.'s (2009) estimates of Familiarity (know old knownew). The absence of stereotype threat effects on Familiarity in Hess et al.'s (2009) study, therefore, cannot be entirely explained by the use of different formulas. However, it could be explained by some methodological issues, as suggested earlier in this paper. In Hess et al. (2009), both the 10 minutes retention interval and guess response modality may have produced a floor effect on Familiarity estimate (see Yonelinas, 2002; Yonelinas \& Levy, 2002), thereby preventing stereotype threat effects to occur. In line with this idea, the elimination of the retention interval and of the guess response modality in the present research led to stereotype threat effects on both Hess et al.'s (2009) and Yonelinas and Jacoby's (1995) Familiarity estimate. Likewise, we obtained higher proportions of know responses across conditions $($ Molder adults $=.27)$ than Hess et al. (around .10$)$, and our Familiarity estimate $\left(M_{\text {older adults }}=.37\right)$ was also consistent with the aging literature $(M=.40$, 
on average, based on Yonelinas' appendix, 2002). All these observations support the idea that Hess et al.'s (2009) study underestimated Familiarity. However, this does not mean that a retention interval and guess responses are intrinsically problematic and cannot provide interesting information ${ }^{2}$. It remains that the exclusion of the retention interval and the guess response in our research allows stereotype threat to occur on Familiarity. Thus, our findings can reasonably be taken as evidence that stereotype threat increases familiarity processes while decreasing Recollection or controlled access to memory in the R/K paradigm. As such, the present results indicate that stereotype threat alters the subjective experience of memory, leading older adults to the impression that an event was experienced previously (sounds familiar) while failing to recall any contextual details about this event.

The present results also offer new evidence that stereotype threat can be rooted in distinct yet not necessarily antagonistic mechanisms, since impaired controlled processes and increased Familiarity may occur simultaneously under threat. These two types of processes have been examined separately and thought as competing explanations in stereotype threat research on gender math stereotypes (Ben-Zeev, Fein \& Inzlicht, 2005; Jamieson \& Harkins, 2007, 2009; Schmader et al., 2008). However, Mazerolle et al. (2012) provided first evidence that these two competing processes may underlie stereotype threat effects, a conclusion that is also supported by the current findings. We believe that this integrative pattern (decreased controlled processes with increased Familiarity or automatic processes) holds for other types of stereotype threat contexts (e.g., gender stereotype in the math domain). Such a pattern has even been found under other types of socio-evaluative threat (also implying the presence of potentially threatening others) both in humans (Belletier et al., 2015; Huguet, Dumas, \& Monteil, 2004) and nonhuman primates (Fagot, Marzouki, Huguet, Gullstrand, \& Claidiere, in press ; Huguet et al., 2014). ${ }^{3}$

Future research. It is noteworthy that we found stereotype threat effects while using a 
relatively impoverished encoding task (counting letters in the word). One may wonder whether these effects can be replicated using a deeper depth of encoding strategy like a selfreference study task (e.g., Colton, Leshikar, \& Gutchess, 2013), which may make R/K decisions easier and thus prevent stereotype threat in older adults. However, a deeper depth of encoding strategy like a self-reference study task may also promote a self-focused attention that, in turn, may ironically exacerbate stereotype threat effects (see Schmader et al., 2008). Future research should clarify this interesting point.

There is also growing evidence that stereotype threat induces a prevention focus (rather than a promotion focus) in which people become concerned with avoiding errors and are sensitive to the presence or absence of losses within their environment (Barber \& Matther, 2013a, 2013b; Grimm \& al., 2009). One question that arises here is whether a prevention focus drives the present pattern (decreased Recollection and increased Familiarity in older adults under threat). If it were the case, then increased Familiarity could reflect, at least in part, a more stringent criterion for responding remember under threat (see also Popham \& Hess, 2015). After all, remember responses being more demanding in terms of memory details, it may be tempting to choose know responses in order to minimize errors on remember responses. This issue is of particular importance to disentangle the role of motivational and cognitive processes underlying stereotype threat effects in older adults' subjective experience of memory. Here, participants' span scores did not moderate the observed effects. This lack of cognitive moderation contradicts other research on gender stereotypes indicating that stigmatized individuals with a dispositionally high working memory capacity resist stereotype threat (Régner et al., 2010). It is yet in line with recent research on aging stereotypes in which this moderation was not found (Barber \& Mather, 2013a; Popham \& Hess, 2015). Taken together, all these findings suggest that stereotype threat leads to underperformance through somewhat different pathways in older and younger 
adults (see Popham \& Hess, 2015).

More generally, our results strongly suggest that stereotype threat exacerbates the well-known age-related differences in the $\mathrm{R} / \mathrm{K}$ paradigm (decreased Recollection and stable otherwise slightly increased Familiarity). By altering the feeling that one is able to remember well, stereotype threat may reinforce doubts and fears and lead to underperformance and stereotype confirmation in older adults facing memory tasks. This is an important issue as older adults are likely to experience stereotype threat during neuropsychological testing. Because of the lengthening of life expectancy, more and more people are concerned with the effects of aging on their mental faculties (e.g., memory decline) and with the possibility of getting Alzheimer's disease or other forms of dementia. Such a concern already results in a growing demand for standardized neuropsychological testing, which contributes to the still challenging issue of accurate diagnosis of Alzheimer's disease in its early stage. As outlined by Haslam et al. (2012; see also Scholl \& Sabat, 2008), the effects of stereotype threat on older adults' memory performance are readily observable and fairly easy to produce with the instructions typically used in clinics to prepare a person for memory testing. Our findings add to this issue by indicating that aging stereotypes can bias older adults feelings of remembering.

Finally, it is noteworthy that this bias was obtained in our research by simply informing older participants about the presence of younger participants (without mentioning any expected age-related differences in performance), an information that is probably given to (or can easily be inferred by) older adults in many aging studies or during neuropsychological testing in clinical settings. The present results therefore strengthen the view that nullifying stereotype threat is needed to ensure valid memory testing in older adults. Without denying that aging may be associated with cognitive decline for many people, we suggest that more attention should be paid to the intervention of aging stereotypes during 
Running head: STEREOTYPE THREAT AND MEMORY

older adults memory assessments. 
Electronic Supplementary Material

ESM 1. Mean number of Remember and Know responses for targets and distracters as a function of threat and age group (standard deviations in parentheses). 
References

Ambady, N., Shih, M., Kim, A., \& Pittinsky, T. L. (2001). Stereotype susceptibility in children: Effects of identity activation on quantitative performance. Psychological Science, 12, 385-390. doi: 10.1111/1467-9280.00371

Barber, S. J., \& Mather, M. (2013a). Stereotype threat can both enhance and impair older adults' memory. Psychological Science, 24, 2522-2529. doi: $10.1177 / 0956797613497023$

Barber, S. J., \& Mather, M. (2013b). Stereotype threat can reduce older adults' memory errors. The Quarterly Journal of Experimental Psychology, 66, 1888-1895. doi: $10.1080 / 17470218.2013 .840656$

Belletier, C., Davranche, K., Tellier, I., Dumas, F., Hasbroucq, T., Vidal, F., \& Huguet, P (2015). Choking under monitoring pressure: Being watched by the experimenter reduces executive attention. Psychonomic Bulletin \& Review. DOI 10.3758/s13423-0150804-9

Beilock, S. L. \& Carr, T. H. (2005). When high-powered people fail: Working memory and "choking under pressure" in math. Psychological Science, 16, 101-105. doi: 10.1111/j.0956-7976.2005.00789.x

Beilock, S. L., \& DeCaro, M. S. (2007). From poor performance to success under stress: Working memory, strategy selection, and mathematical problem solving under pressure. Journal of Experimental Psychology: Learning, Memory, \& Cognition, 33, 983998. doi: $10.1037 / 0278-7393.33 .6 .983$

Beilock, S. L., Rydell, R. J., \& McConnell, A. R. (2007). Stereotype threat and working memory: Mechanisms, alleviation, and spill over. Journal of Experimental Psychology: General, 136, 256-276. doi : 10.1037/0096-3445.136.2.256 
Ben-Zeev, T., Fein, S., \& Inzlicht, M. (2005). Arousal and stereotype threat. Journal of Experimental Social Psychology, 41(2), 174-181. doi: 10.1016/j.jesp.2003.11.007

Chasteen, A., Kang, S., \& Remedios, J. (2012). Aging and stereotype threat: Development, process and interventions. In M. Inzlicht \& T. Schmader (Eds.), Stereotype Threat: Theory, Process, and Application, 202 - 216. Oxford, UK: Oxford University Press. doi: 10.1093/acprof:oso/9780199732449.003.0013

Colton, G., Leshikar, E. D., \& Gutchess, A. H. (2013). Age Differences in Neural Response to Stereotype Threat and Resiliency for Self-Referenced Information. Frontiers in Human Neuroscience, 7(537). doi: 10.3389/fnhum.2013.00537

Conty, L., Gimmig, D., Belletier, C., George, N., \& Huguet, P. (2010). The cost of being watched: Stroop interference increases under concomitant eye contact. Cognition, 115, 133-139. doi: 10.1016/j.cognition.2009.12.005

Croizet, J. C., \& Claire, T. (1998). Extending the concept of stereotype and threat to social class: The intellectual underperformance of students from low socioeconomic backgrounds. Personality and Social Psychology Bulletin, 24, 588-594. doi: $10.1177 / 0146167298246003$

Delaloye, C., Ludwig, C., Borella, E., Chicherio, C., \& de Ribaupierre, A. (2008). L'Empan de Lecture comme épreuve mesurant la capacité de mémoire de travail: Normes basées sur une population francophone de 775 adultes jeunes et âgés. European Review of Applied Psychology, 58, 89-103. doi: 10.1016/j.erap.2006.12.004

Desrichard, O., \& Köpetz, C. (2005). A threat in the elder: The impact of taskinstructions, self-efficacy and performance expectations on memory performance in the elderly. European Journal of Social Psychology, 35, 537-552. doi: 10.1002/ejsp.249 
Eichenbaum H, Yonelinas AP, \& Ranganath C (2007). The medial temporal lobe and recognition memory. Annual Review of Neuroscience, 30, 123-152. doi: 10.1146/annurev.neuro.30.051606.094328

Fagot, J., Marzouki, Y., Huguet, P., Gullstrand, J., \& Claidière, N. (in press). Using a network of computerized ALDM test systems for the assessment of social cognition in nonhuman primates. Journal of Visualized Experiments.

Gardiner, J. M., \& Richardson-Klavehn, A. (2000). Remembering and knowing. In E. Tulving \& F. I. M. Craik (Eds.), The Oxford Handbook of memory (pp. 229-244). Oxford: Oxford University Press.

Gimmig, D., Huguet, P., Caverni, J-P., \& Cury, F. (2006). Choking under pressure and working-memory capacity: When performance pressure reduces fluid intelligence. Psychonomic Bulletin and Review, 13(6), 1005-1010. doi: 10.3758/bf03213916

Grimm, L. R., Markman, A. B., Maddox, W.,T., \& Baldwin, G. C. (2009). Stereotype threat reinterpreted as a regulatory mismatch. Journal of Personality and Social Psychology, 96, 288-304. doi: 10.1037/a0013463

Haslam, C., Morton, T. A., Haslam, S. A., Varnes, L., Graham, R., \& Gamaz, L. (2012). "When the age is in, the wit is out": Age-related self-categorization and deficit expectations reduce performance on clinical tests used in dementia assessment. Psychology and Aging, 27(3), 778-784. doi: 10.1037/a0027754

Hess, T. M., Auman, C., Colcombe, S. J., \& Rahhal, T. A. (2003). The impact of stereotype threat on age differences in memory performance. Journal of Gerontology: Psychological Sciences, 58B, 3-11. doi: 10.1093/geronb/58.1.P3

Hess, T. M., Emery, L. J., \& Queen, T. L. (2009). Task demands moderate stereotype threat effects on memory performance. Journal of Gerontology Series B: Psychological Sciences, 64, 482-486. doi: 10.1093/geronb/gbp044 
Hirshman, E. (1998). On the utility of the signal detection model of the RememberKnow paradigm. Consciousness and Cognition, 7, 103-107. doi:10.1006/ccog.1998.0330

Huguet, P., Barbet, I., Belletier, C., Monteil, J.-M., \& Fagot, J. (2014). Cognitive control under social influence in baboons. Journal of Experimental Psychology: General, 143, 2067-2073. doi: 10.1037/xge0000026

Huguet, P., Dumas, F., \& Monteil, J.M. (2004). Competing for a desired reward in the Stroop task : When attentional control is unconscious but effective versus conscious but ineffective. Canadian Journal of Experimental Psychology, 58, 153-167. doi: $10.1037 / \mathrm{h} 0087441$

Huguet, P., Galvaing, M.P., Monteil, J.M., Dumas, F. (1999). Social presence effects in the Stroop task : Further evidence for an attentional view of Social Facilitation. Journal of Personality and Social Psychology, 77, 1011-1025. doi: 10.1037//0022-3514.77.5.1011

Huguet, P., Régner, I. (2007). Stereotype threat among school girls in quasi-ordinary classroom circumstances. Journal of Educational Psychology, 99, 545-560. doi: 10.1037/0022-0663.99.3.545

Huguet, P., \& Régner, I. (2009). Counter-stereotypic beliefs in math do not protect school girls from stereotype threat. Journal of Experimental Social Psychology, 45, 10241027. doi:10.1016/j.jesp.2009.04.029

Jacoby, L. L. (1991). A process dissociation framework: Separating automatic from intentional uses of memory. Journal of Memory and Language, 30(5), 513-541. doi: $10.1016 / 0749-596 x(91) 90025-f$

Jamieson, J. P., \& Harkins, S. G. (2007). Mere effort and stereotype threat performance effects. Journal of Personality and Social Psychology, 93, 544-564. doi: $10.1037 / 0022-3514.93 .4 .544$ 
Jamieson, J.P., \& Harkins, S.G. (2009). The effect of stereotype threat on quantitative GRE problems: A mere effort interpretation. Personality and Social Psychology Bulletin, 35, 1301-1314. doi:10.1177/0146167209335165

Kang, S. K., \& Chasteen, A. L. (2009). The moderating role of age-group identification and perceived threat on stereotype threat among older adults. International Journal of Aging and Human Development, 69, 201-220. doi:10.2190/AG.69.3.c

Levy, B. R. (1996). Improving memory in old age by implicit self-stereotyping. Journal of Personality and Social Psychology, 71, 1092-1107. doi: 10.1037/00223514.71.6.1092

Mazerolle, M., Régner, I., Morisset, P., Rigalleau, F., \& Huguet, P. (2012). Stereotype threat strengthens automatic recall and undermines controlled processes in older adults. Psychological Science, 23, 723- 727. doi: 10.1177/0956797612437607

McCabe, D. P., Roediger, H. L., III, McDaniel, M. A., \& Balota, D. A. (2009). Aging reduces veridical remembering but increases false remembering: Neuropsychological test correlates of remember-know judgments. Neuropsychologia, 47(11), 2164-2173. doi: 10.1016/j.neuropsychologia.2008.11.025

Monfardini, E. Redouté, J. Hadj-Bouziane, F., Hynaux, C. Fradin, J., Huguet, P., Costes, N., \& Meunier, M. (in press). Others' sheer presence boosts brain activity in the attention (but not the motivation) network. Cerebral Cortex.

Parkin, A. J., \& Walter, B. M. (1992). Recollective experience, normal aging, and frontal dysfunction. Psychology and Aging, 7, 290-298. doi: 10.1037//0882-7974.7.2.290

Perfect TJ, Dasgupta ZR (1997). What underlies the deficit in reported recollective experience in old age? Memory And Cognition, 25 (6), 849-858. doi: dx.doi.org/10.3758/BF03211329 
Popham, L. E., \& Hess, T. M. (2015). Age differences in the underlying mechanisms of stereotype threat. Journal of Gerontology Series B: Psychological Sciences and Social Sciences. doi: 10.1093/geronb/gbt093

Quinn, D. M., \& Spencer, S. J. (2001). The Interference of Stereotype Threat With Women's Generation of Mathematical Problem-Solving Strategies. Journal of Social Issues, 57(1), 55-71. doi: 10.1111/0022-4537.00201

Rahhal, T. A., Hasher, L., \& Colcombe, S. J. (2001). Instructional manipulations and age differences in memory: Now you see them; now you don't. Psychology and Aging, 16, 697-706. doi: 10.1037//0882-7974.16.4.697

Régner, I., Smeding, A., Gimmig, D., Thinus-Blanc, C., Monteil, J.M., \& Huguet, P. (2010). Individual Differences in Working Memory Moderate Stereotype-Threat Effects. Psychological Science, 21, 1646- 1648. doi: 10.1177/0956797610386619

Régner, I., Steele, J. R., Ambady, N., Thinus-Blanc, C., \& Huguet, P. (2014). Our future scientists : A review of stereotype threat in girls from early elementary school to middle school. International Review of Social Psychology, 27, 13-51.

Sharma, D., Massey-Booth, R., Brown, R.J., \& Huguet, P. (2010). Exploring the temporal dynamics of social facilitation in the Stroop task. Psychonomic Bulletin \& Review, $17,52-58$

Schmader, T., \& Johns, M. (2003). Converging evidence that stereotype threat reduces working memory capacity. Journal of Personality and Social Psychology, 85, 440452. doi: $10.1037 / 0022-3514.85 .3 .440$

Schmader, T., Johns, M., \& Forbes, C. (2008). An integrated process model of stereotype threat effects on performance. Psychological Review, 115, 336-356. doi: $10.1037 / 0033-295 X .115 .2 .336$ 
Scholl, J. M., \& Sabat, S.R. (2008). Stereotypes, stereotype threat and aging: Implications for the understanding and treatment of people with Alzheimer's disease. Aging \& Society, 28, 103-130. doi: 10.1017/S0144686X07006241

Spencer, S. J., Steele, C. M., \& Quinn, D. M. (1999). Stereotype threat and women's math performance. Journal of Experimental Social Psychology, 35, 4-28. doi: 10.1006/jesp.1998.1373

Steele, C. M., \& Aronson, J. (1995). Stereotype threat and the intellectual test performance of African-Americans. Journal of Personality and Social Psychology, 69, 797811. doi: $10.1037 / 0022-3514.69 .5 .797$

Stein, R., Blanchard-Fields, F., \& Hertzog, C. (2002). The effects of age-stereotype priming on memory in older adults. Experimental Aging Research, 28, 169-181. doi: $10.1080 / 03610730252800184$

Thomas, A. K., \& Dubois, S. J. (2011). Reducing the Burden of Stereotype Threat Eliminates Age Differences in Memory Distortion. Psychological Science, 22(12), 15151517. doi: $10.1177 / 0956797611425932$

Tombaugh, T. N., \& McIntyre, N. J. (1992). The Mini-Mental State Examination: A comprehensive review. Journal of the American Geriatric Society, 40, 935-992.

Tulving, E.(1985). Memory and consciousness. Canadian Psychology, 26, 1-12. doi: $10.1037 / \mathrm{h} 0080017$

Vann, S. D., Tsivilis, D., Denby, C. E., Quammec, J. R., Yonelinas, A. P., Aggleton, J. P., Montaldi, D. \& Mayes, A. R. (2009). Impaired recollection but spared familiarity in patients with extended hippocampal system damage revealed by 3 convergent methods. Proceedings of the Natural Academy of Sciences of the USA, 106, 5442-5447. doi: 10.1073/pnas.0812097106 
Wixted, J. T. \& Mickes, L. (2010). A Continuous Dual-Process Model of Remember/Know Judgments. Psychological Review, 117, 1025-1054. doi: 10.1037/a0020874

Yonelinas, A. P. (2002). The nature of recollection and familiarity: A review of 30 years of research. Journal of Memory and Language, 46, 441-517. doi: 10.1006/jmla.2002.2864

Yonelinas, A. P., \& Jacoby, L. L. (1995). The relation between remembering and knowing as bases for recognition: Effects of size congruency. Journal of Memory and Language, 34, 622-643. doi: 10.1006/jmla.1995.1028

Yonelinas, A. P., \& Levy, B. J. (2002). Dissociating familiarity from recollection in human recognition memory: Different rates of forgetting over short retention intervals. Psychonomic Bulletin \& Review, 9, 575-582. doi 10.3758/BF03196315

Yonelinas, A. P., Kroll, N., Quamme, J. R., Lazzara, M. M., Sauvé, M. J., Widaman, K. F., \& Knight, R. T. (2002). Effects of extensive temporal lobe damage or mild hypoxia on recollection and familiarity. Nature Neuroscience, 5(11), 1236-1241. doi:10.1038/nn961

Zajonc, R. (1965). Social facilitation. Science, 149, 269-274. doi: 10.1126/science. 149.3681 .269 


\section{Footnotes}

${ }^{1}$ We found stereotype threat effects on Yonelinas and Jacoby's (1995) estimates of Recollection and Familiarity, whereas neither stereotype threat nor age effects were found on the raw data (overall hits and false alarms). This pattern shows how important Yonelinas and Jacoby's (1995) estimates can be: The absence of stereotype threat effects on hits and false alarms does not mean that stereotype threat is not operating. One may argue that Hess et al. (2009) did find a stereotype threat effect on overall hit rates. However, this global effect reflected the fact that stereotype threat appeared only on remember responses (know responses remained unaffected) in their research. In our own research, we found decreased remember responses and increased know responses under threat, a pattern that explains why the stereotype threat effects disappeared when remember and know responses were added to compute overall hits.

${ }^{2}$ For example, participants may sometimes want to respond old for strategic reasons, but find that their memory for the item does not meet the criteria for either a remember or know response. They then face the choice of whether to label the item remember or know. The addition of a guess response could also be helpful if the participant realizes that their first key choice (saying old) was wrong. There are many good methodological reasons for recommending that the $\mathrm{R} / \mathrm{K}$ procedure should include a guess response modality.

${ }^{3}$ It seems that this pattern results exclusively from self-threatening contexts. The presence of non-threatening others, for example, improves (rather than impairs) attention and performance both in humans (Sharma, Massey-Booth, Brown, \& Huguet, 2010) and nonhuman primates (Monfardini, Redouté, Hadj-Bouziane, Hynaux, Fradin, Huguet, Costes, \& Meunier, in press). 


\section{Figure Caption}

Figure 1. Estimates of Recollection (a) and Familiarity (b) as a function of age group and threat condition. Errors bars indicate standard errors of the mean. 


\section{Figure}

Click here to download Figure: Figure 1.pdf

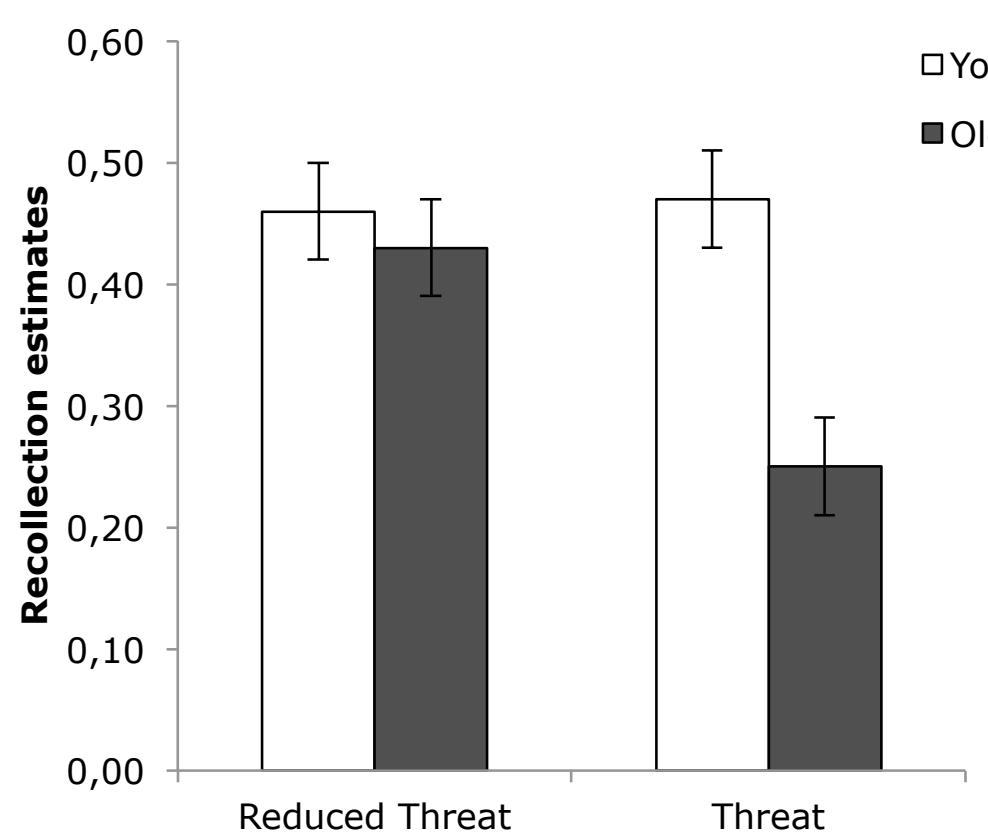

a

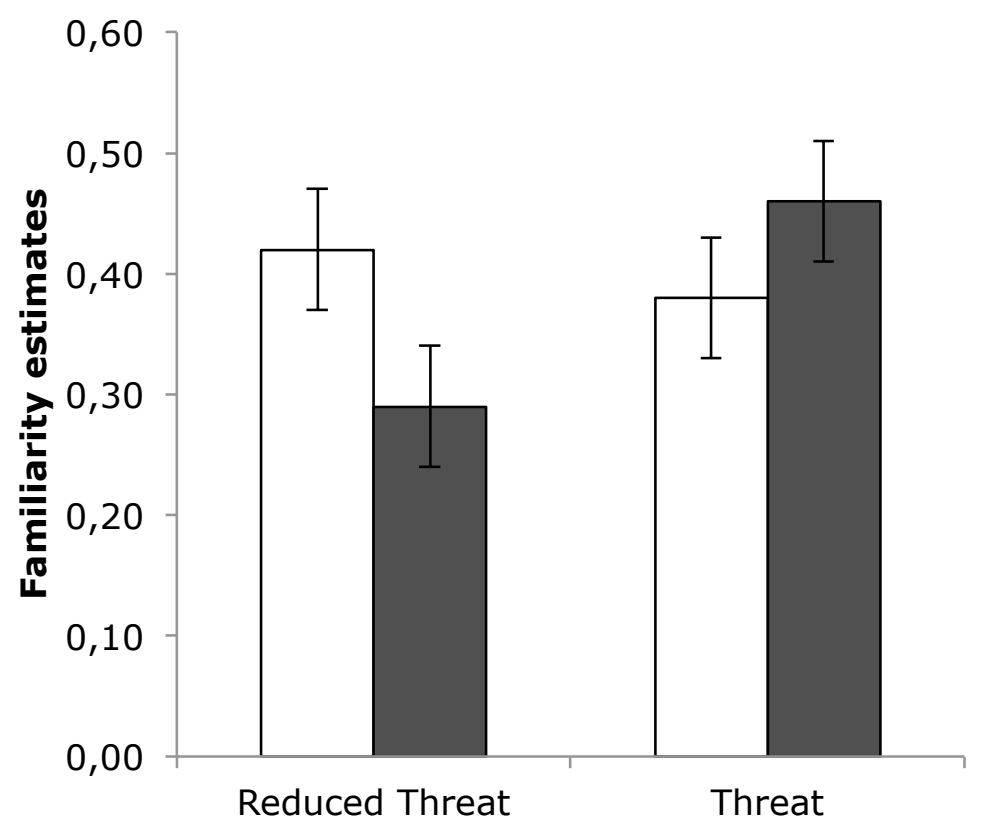

b 